\title{
Colonic Obstruction: A Puzzle to be Solved by Prepared Minds
}

\author{
Kokkinos Ch, Nomikos IN
}

Management of obstruction of the colon and rectum secondary to colorectal cancer (CRC) is challenging in terms of clinical severity, diagnostic and therapeutic options and management of septic and oncological issues.

The following data underline the importance of this topic:

1. Colorectal cancer is the third most commonly diagnosed malignancy, accounting for about 1.4 million new cases per year. It represents the third most common cancer in men (746,000 cases, $10 \%$ of the total) and the second in women $(614,000$ cases, $9.2 \%$ of the total) worldwide; it is the fourth leading cause of cancer death in the world, with almost 700,000 deaths in 2012 [1,2].

2. The incidence of CRC varies by geographical region: the incidence is higher in Europe than in North America, followed by Oceania, Latin America and Africa. However, the trend of CRC appears to vary according to the Human Development Index (HDI), with a variability parallel to changes in diet, smoking and activity patterns, but also the availability of screening programs. A decreasing rate is reported in North America, Oceania and Europe, and in particular in the USA, New Zealand and France; in contrast, an increasing incidence is observed in Latin America, Asia and Eastern Europe [2].

3. Complications of large bowel diseases account for $47 \%$ of gastrointestinal (GI) emergencies [3].

4. CRC presents as an emergency at a rate ranging from 7 to $40 \%$ of the total presentations, but the majority of reports give a figure of around 30\% [3-7].

5. Large bowel obstruction accounts for almost $80 \%$ (occurring in 15-30\% of CRC) of the emergencies related to CRC, while perforation accounts for the remaining $20 \%$ (1-10\% of CRC) [8-10].

6. The most common location of CRC obstruction is the sigmoid colon, with $75 \%$ of the tumors located distal to the splenic flexure [11].

In 2010, the World Society of Emergency Surgery (WSES) issued guidelines for the management of obstructive left colon cancer [12], and in 2017 WSES published the new guidelines which represent both an update and an implementation of the earlier edition [13]. The management

Department of Surgery, "Metaxa" Memorial Cancer Hospital,

Piraeus, Greece

Corresponding author: Nomikos N Iakovos MD FACS,

55 Psarron St., 18120 Koridallos, Piraeus Greece

e-mail: nomikosj@otenet.gr of perforation and obstruction associated with right-sided colon cancer is also included in this recent publication [13].

In this issue of HJS, de Bree and colleagues [14], with their extremely informative review of colonic obstruction, cover a common but difficult problem in the field of emergency surgery and provide us with instructions on how to deal with this entity.

In summary, for obstructive left colon cancer, the selfexpandable metallic stent (SEMS), when available, offers certain advantages compared to emergency surgery; the positioning of SEMS for surgically treatable causes, however, carries some long-term oncological disadvantages, and the relative outcomes are still under analysis. In the setting of emergency surgery, resection and primary anastomosis is preferable to Hartmann's procedure, whenever the characteristics of the patient and the surgeon permit. Right-sided loop colostomy is preferable in rectal cancer, when neoadjuvant treatment is planned.

With regards to the treatment of obstructive right colon cancer, right colectomy is the procedure of choice; alternatives, such as internal bypass and loop ileostomy, are of limited value.

The importance of maintaining an appropriate balance between life-saving surgical procedures and respect for oncological issues must be emphasized. In selected cases, a damage control approach may be required. For all of the above reasons the emergency surgeon should have a strong oncological background and the specialist colorectal surgeon should have a strong background of surgical pathophysiology, emergency surgery and damage control philosophy.

Medical treatment, including appropriate fluid resuscitation, early antibiotic treatment and management of co-existing medical conditions according to international guidelines, must be delivered to all patients at presentation.

In conclusion, de Bree and colleagues offer an extensive overview of the currently available evidence regarding management of large bowel obstruction due to CRC, and at the same time provide a stimulus for surgeons involved in this field to prepare their minds for the most appropriate timely approach to this group of patients.

\section{References}

1. Arnold M, Sierra MS, Laversanne M, et al. Global patterns and trends in colorectal cancer incidence and mortality. Gut 
2017;66:683-91.

2. Torre LA, Siegel RL, Ward EM, et al. Global cancer incidence and mortality rates and trends-an update. Cancer Epidemiol Biomarkers Prev 2016;25:16-27.

3. Zielinski MD, Merchea A, Heller SF, et al. Emergency management of perforated colon cancers: how aggressive should we be? J Gastrointest Surg 2011;15:2232-8.

4. Alvarez JA, Baldonedo RF, Bear IG, et al. Presentation, treatment, and multivariate analysis of risk factors for obstructive and perforative colorectal carcinoma. Am J Surg 2005;190:376-82.

5. Bass G, Fleming C, Conneely J, et al. Emergency first presentation of colorectal cancer predicts significantly poorer outcomes: A review of 356 consecutive Irish patients. Dis Colon Rectum. 2009;52:678-84.

6. Smothers L, Hynan L, Fleming J, et al. Emergency surgery for colon carcinoma. Dis Colon Rectum 2003;46:24-30.

7. Kelley WE Jr, Brown PW, Lawrence W Jr, et al. Penetrating, obstructing, and perforating carcinomas of the colon and rectum. Arch Surg 1981;116:381-4.

8. Gunnarsson H, Holm T, Ekholm A, et al. Emergency presentation of colon cancer is most frequent during summer.
Colorectal Dis 2011;13:663-8.

9. Barnett A, Cedar A, Siddiqui F, et al. Colorectal cancer emergencies. J Gastrointest Cancer. 2013;44:132-42.

10. Laine L, Yang H, Chang SC, et al. Trends for incidence of hospitalization and death due to GI complications in the United States from 2001 to 2009. Am J Gastroenterol. 2012;107:1190-5.

11. Frago R, Ramirez E, Millan M, et al. Current management of acute malignant large bowel obstruction: A systematic review. Am J Surg 2014;207:127-38.

12. Ansaloni L, Andersson RE, Bazzoli F, et al. Guidelines in the management of obstructing cancer of the left colon: Consensus conference of the world society of emergency surgery (WSES) and peritoneum and surgery $(\mathrm{PnS})$ society. World J Emerg Surg 2010;5:29.

13. Pisano M, Zorcolo L, Merli C. 2017 WSES guidelines on colon and rectal cancer emergencies: obstruction and perforation. World J Emerg Surg 2018;13:36.

14. de Bree E, Michelakis D, Stamatiou D, et al. Evidence-based management of acute malignant colorectal obstruction: diverting colostomy as a bridge to elective surgery is a valid alternative. Hellenic J Surg 2018;90:177-85. 